Jul 1st, 12:00 AM

\title{
Uncertainty and Sensitivity Analysis of Control Strategies using the Benchmark Simulation Model No1 (BSM1)
}

Xavier Flores-Alsina

Ignasi Rodríguez-Roda

Gürkan Sin

Krist V. Gernaey

Follow this and additional works at: https://scholarsarchive.byu.edu/iemssconference

Flores-Alsina, Xavier; Rodríguez-Roda, Ignasi; Sin, Gürkan; and Gernaey, Krist V., "Uncertainty and Sensitivity Analysis of Control Strategies using the Benchmark Simulation Model No1 (BSM1)" (2008). International Congress on Environmental Modelling and Software. 49.

https://scholarsarchive.byu.edu/iemssconference/2008/all/49

This Event is brought to you for free and open access by the Civil and Environmental Engineering at BYU ScholarsArchive. It has been accepted for inclusion in International Congress on Environmental Modelling and Software by an authorized administrator of BYU ScholarsArchive. For more information, please contact scholarsarchive@byu.edu, ellen_amatangelo@byu.edu. 


\title{
Uncertainty and Sensitivity Analysis of Control Strategies using the Benchmark Simulation Model N 1 (BSM1)
}

\author{
Xavier Flores-Alsina ${ }^{1,2}$, Ignasi Rodriguez-Roda ${ }^{1}$, Gurkan $\operatorname{Sin}^{2}$ and Krist V. Gernaey ${ }^{2}$ \\ ${ }^{1}$ Laboratory of Environmental and Chemical Engineering, Faculty of Sciences, University \\ of Girona, Campus Montilivi s/n 17071. Girona (Spain) \{xavi, ignasi\}@lequia.udg.es \\ ${ }^{2}$ Center for BioProcess Engineering, Department of Chemical and Biochemical \\ Engineering, Technical University of Denmark, Building 229, DK-2800 Kgs. Lyngby
}

(Denmark)\{xfa,gsi,kvg\}@kt.dtu.dk

\begin{abstract}
The objective of this paper is to perform an uncertainty analysis of the predictions of the Benchmark Simulation Model (BSM) $\mathrm{N}^{0} 1$, when comparing four activated sludge control strategies. The Monte Carlo procedure - an engineering standard, was used to evaluate the uncertainty in the predictions of the BSM1. As input uncertainty of the BSM1, the biokinetic parameters and influent fractions of ASM1 were considered, while for the model predictions the Effluent Quality (EQ) and Operational Cost (OCI) indexes were focused on. The resulting Monte Carlo simulations were presented using descriptive statistics indicating the degree of uncertainty in the predicted EQ and OCI. The Standard Regression Coefficient (SRC) method was used for sensitivity analysis to identify which input parameters influence the uncertainty in the EQ predictions the most. The results show that control strategies including an ammonium $\left(\mathrm{S}_{\mathrm{NH}}\right)$ controller reduce uncertainty in both overall pollution removal and effluent total Kjeldahl nitrogen. Also, control strategies with an external carbon source reduce the effluent nitrate $\left(\mathrm{S}_{\mathrm{NO}}\right)$ uncertainty, but increasing the economical costs and their variability as a trade-off. Finally, the maximum specific autotrophic growth rate $\left(\mu_{\mathrm{A}}\right)$ was found responsible for causing the majority of the variance in the effluent for all the evaluated control strategies. The influence of denitrification related parameters, e.g. $\eta_{\mathrm{g}}$ (anoxic growth rate correction factor) and $\eta_{\mathrm{h}}$ (anoxic hydrolysis rate correction factor), becomes less important when a $\mathrm{S}_{\mathrm{NO}}$ controller manipulating an external carbon source is implemented. These results are meaningful (and expected in a way) from a control engineering point of view: Properly tuned feedback controllers will make the process more robust towards input disturbances, attempting to maintain the process at a predefined setpoint despite input uncertainty (input disturbances), thus ensuring that the output uncertainty of the process is lower compared to for example an open-loop plant. Overall it is found useful to perform uncertainty and sensitivity analysis when comparing different control strategies based on model predictions.
\end{abstract}

Keywords: Uncertainty, sensitivity, control strategies, activated sludge plants, benchmarking, pollution removal efficiency.

\section{INTRODUCTION}

The benchmark simulation model (BSM) is a standardized simulation and evaluation procedure including plant layout, simulation models and model parameters, a detailed description of the disturbances to be applied during testing, and evaluation criteria for testing the relative effectiveness of simulated control strategies in activated sludge plants (Copp, 2002). Computer codes implementing the International Water Association (IWA) activated sludge model (ASM) family (Henze et al., 2000), secondary settling (Takacs et al., 1991), and anaerobic digestion tank models (Batstone et al., 2002) are employed to 
support the decision making on implementation of several technological alternatives such as: control strategies (Vanrolleghem and Gillot, 2002), the addition of new units (Pons and Corriou, 2002, Flores et al., 2007) or operational modes (Ingildsen et al., 2002)

Uncertainty is a central concept when dealing with activated sludge models, whose parameters are inherently subjected to large natural variations. However, the traditional procedure for control strategy evaluation - as e.g. outlined in either the BSM1 (Copp, 2002) or the BSM2 (Jeppsson et al., 2006) - assumes constant rather than variable model parameters, and is thus not capable of taking into account their inherent randomness. Examples of uncertain parameters are the parameters describing the influent COD fractionation, or the parameters describing the effect of temperature or toxic compounds on the model kinetics, which will both have a significant influence on the model predictions.

The Monte Carlo procedure is an engineering standard which is commonly used for evaluating uncertainty in the predictions of simulation models (Helton and Davis, 2003). Monte Carlo simulations are based on a probabilistic sampling method of input uncertainties followed by determination and analysis of the propagation of input uncertainty to model outputs (Helton and Davis, 2003). Even though the topic of uncertainty has been dealt with before in the wastewater treatment field, see e.g. Benedetti et al. (2006), these studies were particularly focused on plant design rather than controller evaluation - the prime focus in this study.

The objective of this paper is to perform an uncertainty analysis of the predictions of the BSM1. Firstly, the Monte Carlo procedure is used to estimate the uncertainty in the predictions of the BSM1. As input uncertainty of the BSM1, the biokinetic parameters and the influent fractions of the ASM1 are considered, while for the model predictions the effluent quality (EQ) and operational costs (OCI) indexes are the main focus. The resulting Monte Carlo simulations were analysed using descriptive statistics indicating the degree of uncertainty in the predicted EQ. Secondly; the Standard Regression Coefficient (SRC) method is used as sensitivity analysis method to identify which input parameters are most influential on the uncertainty in the predictions of EQ.

\section{METHODS}

\section{1 Plant layout, implemented control strategies and evaluation criteria}

The BSM1 plant layout is the activated sludge plant under study. The plant has a modified Ludzack-Ettinger configuration (see Metcalf \& Eddy, 2003) with five reactors in series (tanks ANOX1 \& ANOX2 are anoxic with a total volume of $2000 \mathrm{~m}^{3}$, while tanks AER3, AER4 and AER5 are aerobic with a total volume of $4000 \mathrm{~m}^{3}$ ). These are linked with an internal recycle between the $3^{\text {rd }}$ aerobic (AER3) and the $1^{\text {st }}$ anoxic (ANOX1) tank. The secondary settler has a surface area of $1500 \mathrm{~m}^{2}$ and a total volume of $6000 \mathrm{~m}^{3}$. Further details about the BSM1 design and default (open loop) operational settings can be found in Copp (2002).

Several control strategies $\left[A_{1}, . ., A_{j}, \ldots, A_{5}\right]$ have been implemented in the activated sludge section and were compared to the default open loop base case (see Table 1). The oxygen $\left(\mathrm{S}_{\mathrm{O}}\right)$ sensor is assumed to be ideal, without noise and delay. On the other hand, nitrate nitrogen $\left(\mathrm{S}_{\mathrm{NO}}\right)$ and ammonium nitrogen $\left(\mathrm{S}_{\mathrm{NH}}\right)$ sensor models have a delay of 10 minutes with a zero mean white noise (standard deviation of $0.1 \mathrm{gN} \cdot \mathrm{m}^{-3}$ ).

The evaluation of the overall pollution removal of the plant is obtained by calculating the effluent quality index (EQ) (Eq. 1). Compared to Copp (2002), the EQ was modified to emphasize the effect of ammonia (included in the Kjeldahl nitrogen) on the receiving water: $E . Q=\frac{1}{T \cdot 1000} \int_{t=7 \text { days }}^{t=14 \text { days }}\left(\begin{array}{l}B_{S S} \cdot T S S_{e}(t)+B_{C O D} \cdot C O D_{e}(t)+B_{T K N} \cdot \\ T K N_{e}(t)+B_{N O} \cdot S_{N O, e}(t)+B_{B O D 5} \cdot B O D_{e}(t)\end{array}\right) Q_{e}(t) \cdot d t \quad E q 1$ 
Table 1. Control strategies evaluated in this case study

\begin{tabular}{|c|c|c|c|c|}
\hline Characteristics & $3 \mathrm{DO}$ & $\begin{array}{c}\text { Ammonium } \\
\text { controller }\end{array}$ & $\begin{array}{c}\mathbf{Q}_{\text {intr }} \\
\text { controller }\end{array}$ & $\begin{array}{c}Q_{\text {carb }} \\
\text { controller }\end{array}$ \\
\hline $\begin{array}{c}\text { Measured } \\
\text { variable(s) }\end{array}$ & $\mathrm{S}_{\mathrm{o}}$ in AER1, 2 \& 3 & $\mathrm{~S}_{\mathrm{NH}}$ in AER3 & $\begin{array}{c}\mathrm{S}_{\mathrm{NO}} \text { in } \\
\text { ANOX2 }\end{array}$ & $\begin{array}{c}\mathrm{S}_{\mathrm{NO}} \text { in } \\
\mathrm{ANOX} 2\end{array}$ \\
\hline $\begin{array}{l}\text { Controlled } \\
\text { Variable(s) }\end{array}$ & $\mathrm{S}_{\mathrm{o}}$ in AER1, 2 \& 3 & $\mathrm{~S}_{\mathrm{o}}$ in AER3 & $\begin{array}{c}\mathrm{S}_{\mathrm{NO}} \text { in } \\
\text { ANOX2 }\end{array}$ & $\begin{array}{c}\mathrm{S}_{\mathrm{NO}} \text { in } \\
\mathrm{ANOX} 2\end{array}$ \\
\hline $\begin{array}{c}\begin{array}{c}\text { Setpoint/critical } \\
\text { value }\end{array} \\
\end{array}$ & $\begin{array}{c}2,2 \& 2 \mathrm{~g}(- \\
\mathrm{COD}) \cdot \mathrm{m}^{-3}\end{array}$ & $1 \mathrm{~g} \mathrm{~N} \cdot \mathrm{m}^{-3}$ & $1 \mathrm{~g} \mathrm{~N} \cdot \mathrm{m}^{-3}$ & $1 \mathrm{~g} \mathrm{~N} \cdot \mathrm{m}^{-3}$ \\
\hline $\begin{array}{c}\text { Manipulated } \\
\text { variable }\end{array}$ & $\mathrm{K}_{\mathrm{L}} \mathrm{a}$ & $\begin{array}{l}\mathrm{S}_{\mathrm{o}} \text { setpoint in } \\
\text { 3DO strategy }\end{array}$ & $\mathrm{Q}_{\text {intr }}$ & $Q_{\text {carb }}$ \\
\hline Control algorithm & PI & Cascaded PI & PI & PI \\
\hline Applied in option & $\mathrm{A}_{2}, \mathrm{~A}_{3}, \mathrm{~A}_{4} \& \mathrm{~A}_{5}$ & $\mathrm{~A}_{4} \& \mathrm{~A}_{5}$ & $\mathrm{~A}_{2} \& \mathrm{~A}_{4}$ & $\mathrm{~A}_{3} \& \mathrm{~A}_{5}$ \\
\hline
\end{tabular}

where $\mathrm{TSS}_{\mathrm{e}}, \mathrm{COD}_{\mathrm{e}}, \mathrm{TKN}_{\mathrm{e}}, \mathrm{SNO}_{\mathrm{e}}$ and $\mathrm{BOD}_{\mathrm{e}}$ represent, respectively, the total suspended solids, the chemical oxygen demand, the total Kjeldahl nitrogen, the nitrate nitorgen concentration and the biochemical oxygen demand in the effluent. $Q_{e}$ is the effluent flowrate and $\mathrm{T}$ the time horizon (= 7 last days of simulation). $\mathrm{B}_{\mathrm{SS}}=2, \mathrm{~B}_{\mathrm{COD}}=1, \mathrm{~B}_{\mathrm{TKN}}=30$, $\mathrm{B}_{\mathrm{NO}}=10$ and $\mathrm{B}_{\mathrm{BOD} 5}=2$.

The operational costs index (OCI) is calculated adding the aeration (AE), pumping (PE), mixing (ME), chemical (CS) and sludge production $\left(\mathrm{P}_{\text {sludg }}\right)$ costs as states Eq2

$O C I=A E+P E+M E+3 \cdot C S+5 P_{\text {sludg }}$

\section{2. Uncertainty analysis with Monte Carlo technique}

For notational convenience, the BSM1 model is represented by $\mathrm{f}$, the output vector by $\mathrm{y}$, the state vector by $\mathrm{x}$, the input variables by $\mathrm{u}$, the input parameter vector by $\theta$ and time is represented by $t$ (see details in Eq 3 )

$y(t, \theta)=f(x, u, t, \theta)$

Monte-Carlo analysis of uncertainty involves 3 steps: (1) specifying input uncertainty (2) sampling input uncertainty and (3) propagating the sampled input uncertainty through $\mathrm{f}$ to obtain output uncertainty for $y$. An expert review process was used to define the input uncertainty around the biokinetic parameters and influent fractions of ASM1, while for step 2 we have used Latin Hypercube Sampling (LHS) (McKay et al., 1979).

To carry out this analysis, the uncertainty associated to the ASM1 parameters [U = $\left.U_{1}, \ldots, U_{y}, \ldots U_{32}\right]$ was characterized by a set of probability distributions $[D=$ $\left.D_{1}, \ldots, D_{y}, \ldots D_{32}\right]$. These distributions were assumed to characterize a degree of belief with respect to where the appropriate values for the elements of [U] are located for use in the simulation of the BSM1. When used in this manner, these distributions are providing a quantitative representation of what is referred as subjective or epistemic uncertainty (Helton and Davis, 2003).

Three uncertainty classes are distinguished $\left[C=C_{1}, C_{2}, C_{3}\right]$ to allow the representation of the parameter uncertainty in a structured way, and each uncertainty parameter $U_{\mathrm{y}}$ was assigned to a certain class $\mathrm{C}_{\mathrm{c}}$ depending on the extent of knowledge available in the literature about this specific parameter value. The first class corresponded to low uncertainty and included mostly stoichiometric parameters. In this class $\left(\mathrm{C}_{1}\right)$, the parameters were assumed to have a $5 \%$ upper and lower bound around their default values $\left[U_{1}, \ldots, U_{10}\right]$. The second class $\left(\mathrm{C}_{2}\right)$, corresponded to medium uncertainty and involves kinetic parameters such as the maximum specific growth rate and the affinity constants $\left[U_{11}, \ldots, U_{24}\right]$. In this class, $25 \%$ upper and lower bounds around the default values were assumed. For simplification, all the kinetic and stoichiometric parameters were supposed to be independent although the authors are aware of possible correlations amongst several parameters e.g. the maximum specific growth rate and the half saturation constants. Table 2 summarizes these parameters. 
Table 2. An expert review of input uncertainty of biokinetic parameters of ASM1 including default parameter values, uncertainty class and the corresponding variation percentage

\begin{tabular}{|c|c|c|c|c|c|}
\hline Uncertainty parameter & Symbol & $\begin{array}{c}\text { Default } \\
\text { value }\end{array}$ & Class & $\Delta$ & Units \\
\hline autotrophic yield & $\mathrm{Y}_{\mathrm{H}}$ & 0.67 & 1 & 0.067 & $\mathrm{gCOD} \cdot \mathrm{gN}^{-1}$ \\
\hline heterotrophic yield & $\mathrm{Y}_{\mathrm{A}}$ & 0.24 & 1 & 0.024 & $\mathrm{gCOD} \cdot \mathrm{gCOD}^{-1}$ \\
\hline $\begin{array}{l}\text { fraction of biomass to } \\
\text { particulate products }\end{array}$ & $f_{P}$ & 0.08 & 1 & 0.008 & Dimensionless \\
\hline $\begin{array}{l}\text { fraction of nitrogen in } \\
\text { biomass }\end{array}$ & $\mathrm{i}_{\mathrm{XB}}$ & 0.08 & 1 & 0.008 & $\begin{array}{l}\mathrm{gN}(\mathrm{gCOD})^{-1} \text { in } \\
\text { biomass }\end{array}$ \\
\hline $\begin{array}{l}\text { fraction of nitrogen in } \\
\text { particulate products }\end{array}$ & $\mathrm{i}_{\mathrm{XP}}$ & 0.06 & 1 & 0.006 & $\mathrm{gN}(\mathrm{gCOD})^{-1}$ in $\mathrm{X}_{\mathrm{P}}$ \\
\hline $\begin{array}{l}\text { conversion from COD } \\
\text { particulates }\end{array}$ & $\mathrm{X}_{\mathrm{I} 2 \mathrm{TSS}}$ & 0.75 & 1 & 0.075 & gTSS.(gCOD) $)^{-1}$ \\
\hline $\begin{array}{c}\text { conversion from COD } \\
\text { particulates }\end{array}$ & $\mathrm{X}_{\mathrm{S} 2 \mathrm{TSS}}$ & 0.75 & 1 & 0.075 & gTSS. $(\mathrm{gCOD})^{-1}$ \\
\hline $\begin{array}{l}\text { conversion from COD } \\
\text { particulates }\end{array}$ & $\mathrm{X}_{\mathrm{BH} 2 \mathrm{TSS}}$ & 0.75 & 1 & 0.075 & gTSS. $(\mathrm{gCOD})^{-1}$ \\
\hline $\begin{array}{l}\text { conversion from COD } \\
\text { particulates }\end{array}$ & $\mathrm{X}_{\mathrm{BA} 2 \mathrm{TSS}}$ & 0.75 & 1 & 0.075 & gTSS. $(\mathrm{gCOD})^{-1}$ \\
\hline $\begin{array}{l}\text { conversion from COD } \\
\text { particulates }\end{array}$ & $\mathrm{X}_{\mathrm{U} 2 \mathrm{TSS}}$ & 0.75 & 1 & 0.075 & gTSS. $(\mathrm{gCOD})^{-1}$ \\
\hline $\begin{array}{l}\text { maximum specific } \\
\text { heterotrophic growth rate }\end{array}$ & $\mu_{\mathrm{H}}$ & 4.00 & 2 & 2.00 & day $^{-1}$ \\
\hline $\begin{array}{l}\text { half saturation (hetero. } \\
\text { growth) }\end{array}$ & $\mathrm{K}_{\mathrm{S}}$ & 10.00 & 2 & 5.00 & gCOD. $\mathrm{m}^{-3}$ \\
\hline $\begin{array}{l}\text { half saturation (hetero. } \\
\text { oxygen) }\end{array}$ & $\mathrm{K}_{\mathrm{OH}}$ & 0.20 & 2 & 0.10 & gCOD. $\mathrm{m}^{-3}$ \\
\hline half saturation (nitrate) & $\mathrm{K}_{\mathrm{NO}}$ & 0.50 & 2 & 0.25 & gN.m ${ }^{-3}$ \\
\hline $\begin{array}{l}\text { heterotrophic specific decay } \\
\text { rate }\end{array}$ & $b_{H}$ & 0.30 & 2 & 0.15 & day $^{-1}$ \\
\hline $\begin{array}{l}\text { maximum specific } \\
\text { autotrophic growth rate }\end{array}$ & $\mu_{\mathrm{A}}$ & 0.50 & 2 & 0.25 & day $^{-1}$ \\
\hline half saturation (auto. growth) & $\mathrm{K}_{\mathrm{NH}}$ & 1.00 & 2 & 0.50 & $\mathrm{gN} \cdot \mathrm{m}^{-3}$ \\
\hline half saturation (auto. oxygen) & $\mathrm{K}_{\mathrm{OA}}$ & 0.40 & 2 & 0.20 & gCOD. $\mathrm{m}^{-3}$ \\
\hline $\begin{array}{l}\text { autotrophic specific decay } \\
\text { rate }\end{array}$ & $\mathrm{b}_{\mathrm{A}}$ & 0.05 & 2 & 0.025 & day $^{-1}$ \\
\hline $\begin{array}{l}\text { anoxic growth rate correction } \\
\text { factor }\end{array}$ & $\eta_{\mathrm{g}}$ & 0.80 & 2 & 0.40 & Dimensionless \\
\hline amonification rate & $\mathrm{k}_{\mathrm{a}}$ & 0.05 & 2 & 0.025 & $\mathrm{~m}^{3}(\mathrm{gCOD} \cdot \mathrm{day})^{-1}$ \\
\hline $\begin{array}{l}\text { maximum specific hydrolysis } \\
\text { rate }\end{array}$ & $\mathrm{k}_{\mathrm{h}}$ & 3.00 & 2 & 1.50 & $\underset{\mathrm{gX}}{\mathrm{g}}\left(\mathrm{gX}_{\mathrm{BH}}\right)^{-1} \mathrm{COD} \cdot \mathrm{day}$ \\
\hline half saturation (hydrolysis) & $\mathrm{K}_{\mathrm{X}}$ & 0.10 & 2 & 0.05 & $\mathrm{gX}_{\mathrm{S}}\left(\mathrm{gX}_{\mathrm{BH}} \mathrm{COD}\right)^{-1}$ \\
\hline $\begin{array}{l}\text { anoxic hydrolysis rate } \\
\text { correction factor }\end{array}$ & $\eta_{\mathrm{h}}$ & 0.80 & 2 & 0.40 & Dimensionless \\
\hline
\end{tabular}

The third class of uncertainty $\left(\mathrm{C}_{3}\right)$ corresponded to high uncertainty and included the influent fraction related parameters, assuming upper and lower bounds equal to $50 \%$ of the default parameter values (results not shown). Several class 3 uncertainty factors (from 0.5 to 1.5) were applied to the COD and $\mathrm{N}$ fractions obtained from the influent file included in the BSM1 used to calculate the different ASM1 influent organic and inorganic matter state variables. The different fractions are represented as $\alpha_{i}$ where $i$ is the component e.g. soluble organic matter $S_{s}$, inorganic soluble matter $S_{i}$. A similar method was applied to influent nitrogen $\left[U_{29}, \ldots, U_{32}\right]$, where the fraction coming from particulate products and biomass was removed first, to finally obtain the inorganic (ammonium, $\mathrm{S}_{\mathrm{NH}}$ ) and organic influent nitrogen compounds concentrations (either soluble or particulate, $\mathrm{S}_{\mathrm{ND}}$ and $\mathrm{X}_{\mathrm{ND}}$ ). 
The input uncertainty space was sampled using the LHS method (McKay et al., 1979; Iman et al., 1981). In this study, 1000 samples $\left[U_{y}=U_{y, 1}, \ldots, U_{y, f}, \ldots U_{y, 1000}\right]$ were generated to ensure that the input uncertainty space was covered uniformly. Each Latin hypercube sample contains one randomly selected value $\mathrm{U}_{\mathrm{y}, \mathrm{f}}$ from each of the previously defined probability distributions $\mathrm{D}_{\mathrm{y}}$. The Monte Carlo simulations were performed by evaluating the BSM model for each one of the generated Latin hypercube samples, solving the entire model and quantifying the defined EQ criterion for each tested alternative [A]. The solution of the model for each parameter combination resulted in a distribution of possible values for the defined evaluation criteria (Eq 1 and 2). These distributions reflected the possible variation of the performance criterion taking into account the input uncertainty.

\subsection{Sensitivity Analysis}

The sensitivity analysis phase involves the construction (see Eq 4) of a regression model that reveals the relationships between the elements associated to the input uncertainty $[U=$ $\left.\left\{U_{1}, \ldots, U_{k}, \ldots, U_{32}\right\}\right]$ and the elements associated to the output uncertainty i.e. in this case EQ (Saltelli et al., 2005).

$$
X_{j}=b_{0}+\sum_{k=1}^{n S} b_{k} U_{k}
$$

The higher the value of the regression coefficient $\left(b_{k}\right)$ the stronger the relationship is, i.e input uncertainty values are auto-scaled. The absolute values of the regression coefficients are ranked and categorized by k-means clustering (Hair el al., 1998).

\section{RESULTS}

All dynamic simulations were preceded by a steady state simulation to ensure an appropriate starting point for the dynamic simulations and to eliminate bias due to the selection of the initial conditions on the dynamic modelling results (Copp, 2002). Even though the length of the dynamic influent file used to carry out the simulations was 28 days, only the data generated during the last seven days were used to evaluate the plant performance.
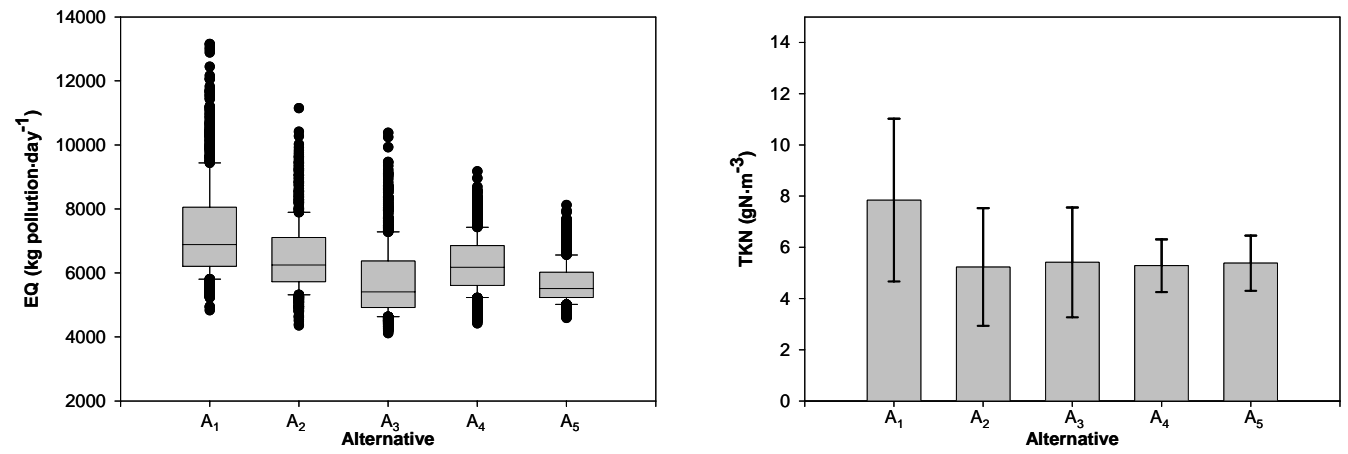

Figure 2. Representation of the output uncertainty for the evaluated control strategies using multiple box plots for EQ (left) and error bar charts for the effluent TKN (right).

The results of the uncertainty analysis are shown using multiple box-plots for the EQ after running 1000 Monte Carlo simulations for each of the control strategies (Figure 2). From the results depicted in Figure 2 (left), it can be noticed that there is a clear difference between the alternatives with $\left(\mathrm{A}_{2}, \mathrm{~A}_{3}, \mathrm{~A}_{4}\right.$ and $\left.\mathrm{A}_{5}\right)$ and without $\left(\mathrm{A}_{1}\right)$ controllers in terms of both absolute value and variance. Also one observes the effect of the $\mathrm{S}_{\mathrm{NH}}$ controller $\left(\mathrm{A}_{4}\right.$ and $\mathrm{A}_{5}$ ) in reducing even more the variation of the potential impact on the receiving water. This is mainly due to the continuous adaptation of the $S_{O}$ set-point via the cascade controller which ensures a constant effluent $S_{\mathrm{NH}}$ level as shown by the error bar chart in Figure 2 (right). 

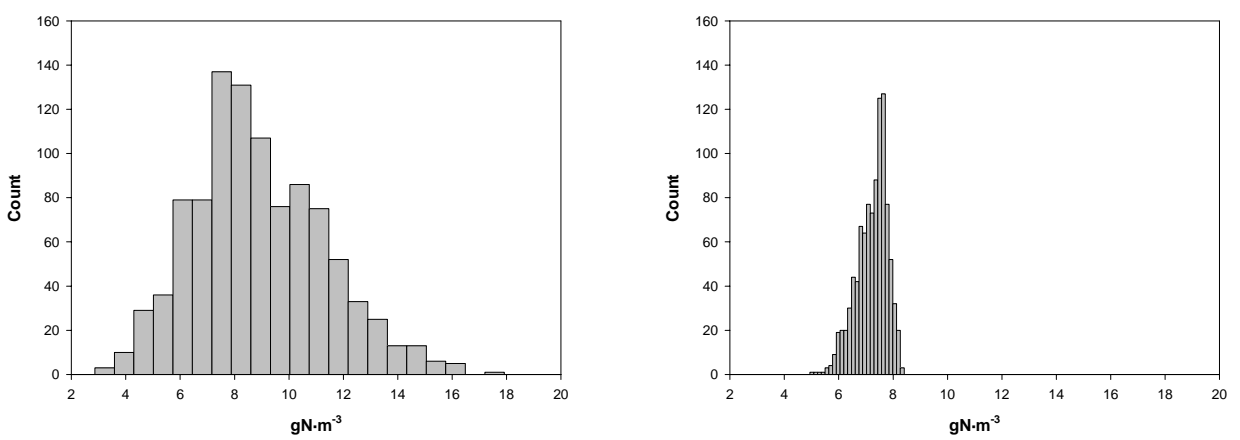

Figure 3. Histograms of the effluent $S_{\mathrm{NO}}$ when alternative $A_{1}$ (left) and $A_{3}$ (right) are evaluated under uncertainty

Also, it is important to point out the effect of the external carbon source controller on the overall nitrogen removal. The external carbon source addition provides the limited readily biodegradable substrate for denitrification, thereby enhancing the total nitrogen removal by improving the reduction of the nitrate to nitrogen gas. In this way, the external carbon controller ultimately decreases the variation of the effluent $\mathrm{S}_{\mathrm{NO}}$ as shown by the histograms of Figure 3. Again, this result was expected for a properly functioning controller, which will make the system more robust and thus reduce the output uncertainty.

Table3. Mean and standard deviation of the operation costs breakdown for the different generated alternatives under uncertainty

\begin{tabular}{cccccc}
\hline & $\mathbf{A}_{\mathbf{1}}$ & $\mathbf{A}_{\mathbf{2}}$ & $\mathbf{A}_{\mathbf{3}}$ & $\mathbf{A}_{\mathbf{4}}$ & $\mathbf{A}_{\mathbf{5}}$ \\
\hline$A E$ & 3495,75 & 3489,23 & 3630,63 & 3773,32 & 4047,59 \\
& 0,00 & 218,03 & 220,84 & 631,55 & 681,66 \\
$P E$ & 388,17 & 250,20 & 388,17 & 266,12 & 388,17 \\
& 0,00 & 48,82 & 0,00 & 57,38 & 0,00 \\
$3 \cdot C S$ & 0,00 & 0,00 & 2652,46 & 0,00 & 2455,84 \\
& 0,00 & 0,00 & 898,97 & 0,00 & 1109,36 \\
$5 \cdot S P$ & 12198,21 & 12228,04 & 13579,12 & 12207,36 & 13511,42 \\
& 912,38 & 905,39 & 1200,85 & 1057,24 & 1260,23 \\
OCI & 16322,13 & 16207,47 & 20490,37 & 16486,33 & 20643,02 \\
& 912,38 & 779,79 & 1819,72 & 1229,88 & 2504,78 \\
\hline
\end{tabular}

The results of Table 3, where it is represented the mean and standard deviation of the breakdown of the operational costs; demonstrate a clear difference between the control strategies with and without external carbon source addition. The periodic purchase of an external carbon source implies a subsequent increase of both quantity and variation of the sludge production and the overall operating cost index. Hence, it can be said that the addition of external carbon source reduces the effluent nitrate and its variability as a tradeoff to an increase of the operation costs and their variability. ME doe not present variation from one alternative to the others and thus not included in the table. Control strategies with a $\mathrm{S}_{\mathrm{No}}$ controller manipulating the internal recycle and $\mathrm{S}_{\mathrm{NH}}$ manipulating the oxygen setpoint have higher variability in pumping and aeration energy because the controllers in order to maintain the nitrate concentration in ANOX2 and AER3 to the desired setpoint $1 \mathrm{gN} \cdot \mathrm{m}^{-3}$. From a control engineering point of view, this simply tells that the controller does fulfil its function which is to maintain a stable process performance despite input disturbances, meaning less variability in the effluent compared to the open-loop case.

Table 4. Summary of sensitivity analysis results: Standardized Regression Coefficients (SRC) of parameters clustered into three classes for all the evaluated control strategies

\begin{tabular}{lccccc}
\hline & $\mathbf{A}_{\mathbf{1}}$ & $\mathbf{A}_{\mathbf{2}}$ & $\mathbf{A}_{\mathbf{3}}$ & $\mathbf{A}_{\mathbf{4}}$ & $\mathbf{A}_{\mathbf{5}}$ \\
\hline Strong & $\mu_{\mathrm{A}}$ & $\mu_{\mathrm{A}}$ & $\mu_{\mathrm{A}}$ & $\mu_{\mathrm{A}}$ & $\mu_{\mathrm{A}}$ \\
& $\mathrm{b}_{\mathrm{A}}, \mathrm{K}_{\mathrm{OA}}, \mathrm{b}_{\mathrm{H}}$, & $\mathrm{b}_{\mathrm{A}}, \alpha_{\mathrm{SNH}}$, & $\mathrm{b}_{\mathrm{A}}, \alpha_{\mathrm{SNH}}$, & $\mathrm{b}_{\mathrm{A}}, \eta_{\mathrm{h}}, \eta_{\mathrm{g}}$, & $\mathrm{b}_{\mathrm{A}}, \alpha_{\mathrm{SNH}}$, \\
& $\mathrm{K}_{\mathrm{NH}}, \eta_{\mathrm{g}}, \mathrm{Y}_{\mathrm{H}}$ & $\alpha_{\mathrm{XND}}, \mathrm{K}_{\mathrm{OA}}$, & $\alpha_{\mathrm{XND}}, \mathrm{K}_{\mathrm{OA}}$ & $\mathrm{Y}_{\mathrm{H},} \mathrm{K}_{\mathrm{OA}}$, & $\mathrm{K}_{\mathrm{NH}}, \alpha_{\mathrm{XND}}$ \\
and $\eta_{\mathrm{h}}$ & $\mathrm{K}_{\mathrm{NH}}$ and $\eta_{\mathrm{g}}$, & and $\mathrm{K}_{\mathrm{NH}}$ & $\mathrm{K}_{\mathrm{OH}}$ & and $\mathrm{K}_{\mathrm{OA}}$ \\
\hline
\end{tabular}


Using the Monte Carlo simulation results for EQ, the standardized regression coefficients for each input were calculated, and are presented in Table $\mathbf{4}$ for each control strategy. From the results generated during the sensitivity analysis one observes that the parameters related to the nitrification process, e.g. $\mu_{\mathrm{A}}$, and the denitrification process, e.g. $\eta_{\mathrm{g}}$, are identified as the most influential. This is understandable since TKN (30) and NO (10) are the most important factors in the EQ calculation. Moreover, it is generally known that the BSM1 plant (Copp, 2002) is highly loaded with nitrogen, meaning that any change in ASM1 parameters influencing nitrogen removal will be noticed in the EQ. In Figure 4, a bi-plot shows the correlation between the EQ (Eq. 1) and the most influential factor found for all the evaluated control strategies $\left(\mu_{\mathrm{A}}\right)$.

On the other hand, for those control strategies with an external carbon source addition $\left(\mathrm{A}_{3}\right.$ and $\mathrm{A}_{5}$ ), denitrification related parameters are classified as weak, i.e. non-influential. This fact is attributed to the improvement of the overall nitrate removal rate due to the extra carbon source added by this controller, thereby reducing the importance of this denitrification process parameter. In other words, the additional input of readily biodegradable organic matter makes the system less dependent on the anoxic correction factors for both hydrolysis $\left(\eta_{h}\right)$ and growth rate $\left(\eta_{\mathrm{g}}\right)$, thus decreasing the variability of the effluent $\mathrm{S}_{\mathrm{NO}}$.
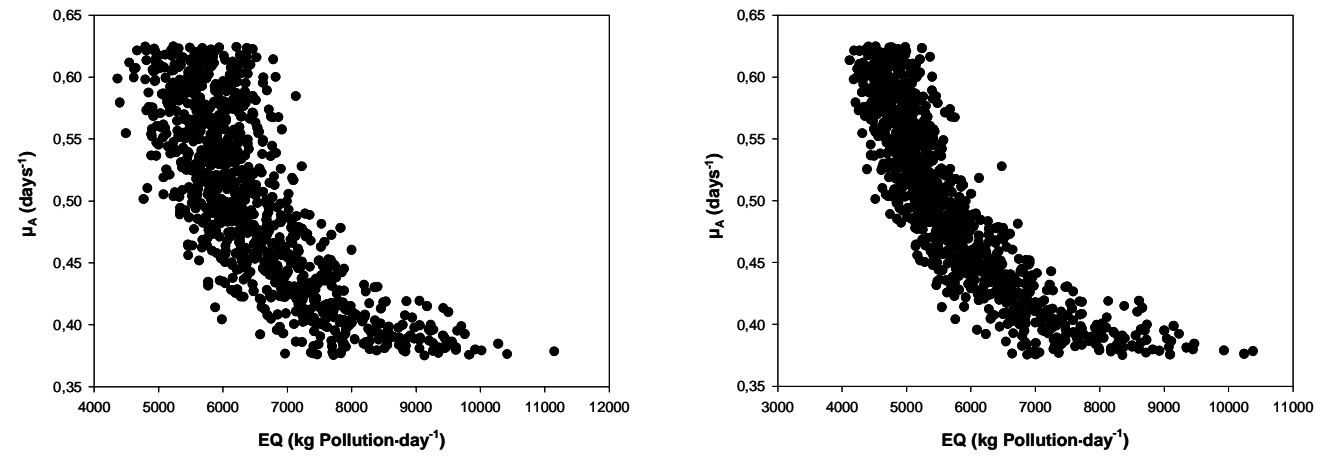

Figure 4. Correlation between the output (EQ) and input $\left(\mu_{\mathrm{A}}\right)$ for alternatives $A_{2}($ left $)$ and $\mathrm{A}_{3}$ (right).

It is important to point out that despite the apparent advantages of the formal assessment of the uncertainty, one should be aware that the conclusions arising from this case study considering uncertainty can only be as good as the underlying assumptions. Thus, the results of the uncertainty analysis will to a large extent depend on the characteristics of the defined uncertainty distributions, similar to a base case performance i.e. without uncertainty, where the results will depend on the model selection

\section{CONCLUSIONS}

This paper has presented the results of performing uncertainty and sensitivity analysis of several activated sludge control strategies using the BSM1. Different combinations of oxygen, nitrate and ammonium controllers were evaluated considering uncertainty in the ASM1 parameters. The input uncertainty, defined by probability distributions, was propagated trough the BSM1 using a Monte Carlo approach which quantified the uncertainty (probability distribution) in the model predictions such as the effluent quality index.

From the evaluated controllers, alternatives with an ammonium controller (Alternatives $\mathrm{A}_{4}$ and $\mathrm{A}_{5}$ ) reduced the uncertainty in the variation of nitrogen removal efficiency mainly due to an improvement in the simulated nitrification rates. The alternatives with a nitrate controller $\left(\mathrm{A}_{3}\right.$ and $\left.\mathrm{A}_{5}\right)$ also reduced the effluent nitrate and its variation, but increasing the operation costs and their variability as a trade-off. This was mainly due to the added carbon source acts as an extra electron donor enhancing the total nitrogen removal by improving the reduction of the produced nitrate to nitrogen gas. 
Finally, the results of the sensitivity analysis revealed that the autotrophic specific growth rate $\left(\mu_{\mathrm{a}}\right)$ is the parameter with the strongest influence on the effluent quality variability. This was attributed to the relatively high weight of TKN in the EQ calculation and to the fact that the plant is highly loaded in N. Also, denitrification related parameters became less important when an external carbon source was added because the additional input of readily biodegradable organic matter made the system less dependent on the anoxic correction factors for hydrolysis $\left(\eta_{\mathrm{h}}\right)$ and growth rate $\left(\eta_{\mathrm{g}}\right)$

The uncertainty analysis results showed input uncertainty may propagate differently to model outputs when applying different control strategies. While some controller type ensures the effluent ammonium concentration is less variable (low uncertainty), the other ensures the effluent nitrate is less variable (less uncertainty). Hence making a decision about which control strategy is better becomes a subject of multi-objective weighting. All in all uncertainty analysis is certainly deemed useful as it provides a more realistic interpretation of the model simulations: hence better informed decisions can be made.

\section{REFERENCES}

Batstone D.J., Keller J., Angelidaki I., Kayuznyi S.V., Pavlostathis S.G., Rozzi A., Sanders W.T.M., Siegrist H. and Vavilin V.A. Anaerobic Digestion Model No 1. IWA STR No 13, IWA Publishing, London, UK, 2002.

Benedetti L., Bixio D., Vanrolleghem P.A. Assessment of WWTP design and upgrade options: balancing costs and risks of standards' exceedance. Wat. Sci. Tech. 54(6-7):371. 2006.

Copp, J.B. The COST Simulation Benchmark: Description and Simulator Manual. Office for Official Publications of the European Community, Luxembourg. 2002.

Flores X., Poch M., Rodríguez-Roda I., Bañares-Alcántara R. and Jiménez L. Systematic procedure to handle critical decisions during the conceptual design of activated sludge systems. Ind. Eng. Chem. Res. 46(17):5600. 2007.

Helton J.C. and Davis F.J. Latin Hypercube Sampling method and the propagation of uncertainty in analyses of complex systems. Reliab. Engng. Syst. Saf. 81:23. 2003.

Hair J. Fr., Andersen R.E., Tatham R.L. and Black W.C: Multivariable Data Analysis. Fifth Edition. Prentice-Hall. London. 1998.

Henze M., Gujer W., Mino T. and van Loosdrecht M.C.M. Activated Sludge Models ASM1, ASM2, ASM2d and ASM3. IWA Scientific and Technical Report No. 9, IWA Publishing, London, UK, 2000.

Iman R.L., Helton J.C. and Campbell J.E.. An approach to sensitivity analysis of computer models, Part 1. Introduction, input variable selection and preliminary variable assessment. J. Qual. Techno1. 13(3):174. 1981.

Ingildsen P., Olsson G. and Yuan Z. A hedging point strategy - balancing effluent quality, economy and robustness in the control of wastewater treatment plants. Wat. Sci. Tech. 45(4-5):317. 2002

Jeppsson U., Rosen C., Alex J., Copp J., Gernaey K.V., Pons M.N. and Vanrolleghem P.A. Towards a benchmark simulation model for plant-wide control strategy performance evaluation of WWTPs. Wat. Sci. Tech. 53(1):287. 2006

McKay M.D., Conover W.J. and Beckman R.J. A comparison of three methods for selecting values of input variables in the analysis of output from a computer code. Technometrics 21:239. 1979.

Metcalf and Eddy. Wastewater Engineering: Treatment, Disposal and Reuse ( $3^{\text {rd }}$ edition). New York: Mc-Graw-Hill. Inc., 2003.

Pons M.N and Corriou J.P. Implementation of storage tanks on the COST 624 benchmark, Wat. Sci. Tech. 45(4-5):159. 2002.

Saltelli A. Sensitivity analysis in practice. A guide to assessing scientific models. Wiley. Chichester. UK.2004.

Takács I., Patry G.G. and Nolasco D. A dynamic model of the clarification-thickening process. Wat. Res. 25(10):1263. 1991. 